\title{
Pharmacological Interventions to Decompression Sickness in Rats: Comparison of Five Agents
}

\author{
Elizabeth A. Montcalm-Smith, Andreas Fahlman, and \\ SUSAN R. KAYAR
}

\begin{abstract}
Montcalm-Smith EA, Fahlman A, Kayar SR. Pharmacological interventions to decompression sickness in rats: comparison of five agents. Aviat Space Environ Med 2008; 79:7-13.

Introduction: This research investigated whether decompression sickness (DCS) risk or severity could be reduced using drug interventions that are easier to implement and equal to or more efficacious than recompression therapy. Methods: Using a rat model of DCS, anti-inflammatory or anticoagulant drugs, including lidocaine, aspirin (ASA), methylprednisolone (MP), alpha-phenyl-N-butylnitrone (PBN), and transsodium crocetinate (TSC) were tested to determine their effect on incidence of DCS, death, and time of symptom onset. Each treatment group consisted of $\sim 40$ animals that received the drug and $\sim 40$ controls. Animals were exposed to one of five compression and decompression profiles with pressure ranging from 6.3 ATA (175 fsw) to 8.0 ATA ( $231 \mathrm{fsw}$ ); bottom time was either 60 or $90 \mathrm{~min}$; and decompression rate was either 1.8 or 15 ATA $\cdot \mathrm{min}^{-1}$. Following decompression, the rats were observed for 30 min while walking on a wheel. DCS was defined as an ambulatory deficit or abnormal breathing. Results: None of the drugs reached statistical significance for all DCS manifestations. Lidocaine post-dive and MP were the only treatments with marginally $(P<0.15)$ significant differences in DCS outcomes compared to controls. Lidocaine post-dive significantly decreased the incidence of neurological DCS from 73-51\%. MP significantly extended the time of onset of death from DCS from $5.4 \mathrm{~min}$ to $7.1 \mathrm{~min}$. Discussion: Of the treatments investigated, lidocaine given post-dive has the best chance of success in adjuvant therapy of DCS. Future studies might investigate adjuvant drugs given in combination or during recompression.

Keywords: DCS, adjunctive therapy, lidocaine, aspirin, methylprednisolone, transsodium crocetinate, alpha-phenyl-N-butylnitorne.
\end{abstract}

$\mathrm{D}_{\mathrm{r}}^{\mathrm{s}}$ ECOMPRESSION sickness (DCS) is a systemic pathophysiological process that may occur with a decrease in atmospheric pressure. The pressure reduction results in bubbles of inert gas, usually nitrogen, within body tissues. Originally, it was believed that the bubbles caused mechanical damage to cells by displacing and deforming adjacent structures, tearing vessels, or obstructing vessels, leading to ischemia (22). However, the full spectrum of pathology found in DCS cannot be explained solely by the hypothesis of bubbleinduced mechanical obstruction of the vasculature (16). It is now believed that the body's host defenses respond to bubbles as foreign bodies, leading to the activation of enzymes, complement and clotting factors, and the release of vasoactive substances (48). The activation of the body's defense system initiates a vicious cycle that leads to multiple organ failure unless the DCS is adequately treated. In fact, the longer the treatment is delayed, the greater the chance of treatment failure, residual symptoms, permanent sequelae, or death (35).
Many parallels may be drawn between Type I DCS and inflammation. It has been suggested that the joint pain, itching, and malaise associated with Type I DCS is caused by bubbles acting as immunogens, stimulating the release of histamine, serotonin, or prostaglandins. These bioactive molecules are associated with an increase in vascular permeability, leading to tissue edema and loss of intravascular volume. Edema in any tissue may sufficiently increase tissue pressure, blocking capillary perfusion, leading to a "no-reflow" phenomenon that promotes ischemic damage and inert gas bubble growth (35). Edema in neurological tissue could damage neurological membranes, perhaps the source of neurodeficits in Type II DCS (33). Reduced intravascular volume itself is a problem that induces a state of shock (16). If the immune system response to bubbles activates leukocytes, these cells may migrate out of the vascular space. While free in the extravascular tissues, leukocytes may release proteolytic enzymes that damage tissues (33). Additionally, the transendothelial migration of leukocytes tends to damage the vessel walls, activating platelets and other blood cells or proteins (38). Plasma proteins such as fibrinogen may cause blood clots and abnormal hemostasis; blood cells may adhere to the damaged wall sites, releasing more histamine, perpetuating the chain of inflammatory events. There is a wide range of possible drug therapies that could reduce or eliminate these problems, depending on the immunological pathway activated.

The purpose of this research was to determine if DCS risk or severity could be reduced using available drug interventions. Drug therapies against DCS have been considered by others, with varying levels of success

From the Naval Medical Research Center, Silver Spring, MD (E. A. Montcalm-Smith, S. R. Kayar), and the UBC Marine Mammal Research Unit, The University of British Columbia, Vancouver, BC, Canada (A. Fahlman).

This manuscript was received for review in February 2007. It was accepted for publication in October 2007.

Address reprint requests to: Diana J. Temple, Naval Medical Research Center, Operational and Undersea Medicine Department, 503 Robert Grant Avenue, Silver Spring, MD 20910-7500; Diana.Temple@ med.navy.mil.

Reprint \& Copyright (C) by the Aerospace Medical Association, Alexandria, VA.

DOI: $10.3357 /$ ASEM.2071.2008 
$(1,2,5,9,34)$. The proposed drug treatments for this study targeted pathophysiological processes that are thought to contribute to the manifestations of DCS and not to prevent bubble formation.

\section{Lidocaine}

Lidocaine is considered the most promising pharmacologic agent for treatment of DCS. Although there are no published randomized trials of lidocaine in humans, anecdotal reports support its use in DCS (12). A sodium channel blocker, lidocaine has been used as a local anesthetic and prophylactic antiarrhythmic agent for ventricular tachycardia and fibrillation (4). It readily crosses the blood-brain barrier (43), has a high volume of distribution, and is rapidly metabolized by the liver. In 1984, Evans et al. (18) demonstrated a protective effect of lidocaine in a feline model of cerebral arterial gas embolism, sparking interest as a potential adjuvant treatment for DCS (18). A rat study found predive intraperitoneal injections of lidocaine reduced DCS from $72-0 \%$ (31). Of the two studies that used lidocaine to treat neurological DCS, one reported no benefit from a 5 - $h$ infusion as an adjunct to recompression in a porcine model (7) and the other reported improvement after lidocaine was added during hyperbaric oxygen treatment (12). Low-dose lidocaine $\left(2 \mathrm{mg} \cdot \mathrm{kg}^{-1}\right)$ inhibits the adhesion of neutrophils to vascular endothelium in rabbits (body mass 2.2 to $2.6 \mathrm{~kg}$ ) (37) and to a nylon fiber column (32). The mechanism by which lidocaine modulates leukocyte activity is unknown; however, regardless of the mechanism, it may offer protection by preventing leukocytes from adhering to damaged endothelium.

We examined lidocaine in a rat model using two different therapeutic strategies. In one series we treated with lidocaine immediately before a dive using a rapid decompression rate that favors neurological symptoms of DCS. In the other series, lidocaine therapy was delivered in several doses immediately after decompression, using a slower ascent rate associated with pulmonary DCS symptoms in addition to neurological symptoms. We used low therapeutic dose levels as this tends to preserve conduction in isolated nerves and inhibits cation leakage (13).

\section{Aspirin (ASA)}

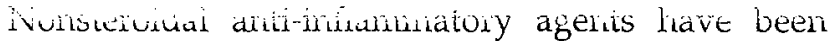
proposed as prophylactics against DCS because they inhibit platelet activation and aggregation. They also suppress the concomitant cascade of inflammatory events and decrease free radicals and superoxide (5). One of the most widely used drugs in the world, ASA exerts its efficacy via acetylation of the cyclooxygenase enzyme (COX). The acetylation occurs rapidly and leads to irreversible inhibition of the COX enzyme (47). Low doses of ASA (30-50 mg $\left.\cdot \mathrm{d}^{-1}\right)$ inhibit the activity of cyclooxygenase type 1 (COX-1), decreasing the production of thromboxane $\mathrm{A}_{2}$ and platelet aggregation (39). Higher doses over longer periods inhibit COX-2 and nonspecifically acetylate a variety of proteins and nucleic acids.
This is the basis for the anti-inflammatory effects (47). ASA is rapidly absorbed, yielding a peak serum level within 1-2 h.

Several laboratories have investigated the effect of ASA on DCS. Popovic and colleagues reported a reduction in DCS incidence from $40 \%$ in untreated control rats to $22 \%$ in rats given ASA $\left(55 \mathrm{mg} \cdot \mathrm{kg}^{-1}\right)$ in their drinking water for $30 \mathrm{~d}$ prior to a dive (41). Philp et al. reported modest but not statistically significant success with ASA, as measured by the reduction in circulating platelet count, when given orally in men ( $325 \mathrm{mg}$ three times per day) for $2 \mathrm{~d}$ prior to diving (40). In contrast, Bennett and Brock reported no benefits from ASA $\left(100 \mathrm{mg} \cdot \mathrm{kg}^{-1}\right)$ administered orally to rats $1 \mathrm{~h}$ predive (3). We, therefore, chose to test if chronic oral administration of a $100 \mathrm{mg} \cdot \mathrm{kg}^{-1}$ dose would affect DCS outcome in a rat model using two protocols: 1) a rapid decompression rate favoring neurological symptoms of DCS (ASA rapid); and 2) a slower decompression rate associated with pulmonary DCS symptoms in addition to the neurological symptoms $\left(\mathrm{ASA}_{\text {slow }}\right)$.

\section{Methylprednisolone (MP)}

An anti-inflammatory steroid, MP has been suggested as a DCS therapy because it may reduce cerebral edema caused by gas emboli (5). MP may also improve blood flow to brain regions injured by gas emboli by reducing the adherence of leukocytes to damaged vascular endothelium (17). In swine subjected to a 24-h saturation dive, MP administered $24 \mathrm{~h}$ prior to decompression did not protect against DCS; in fact, it increased the death rate of animals with DCS (15). However, after $24 \mathrm{~h}$, the MP was probably no longer at its peak activity. Consideration of corticosteroids as emergency therapy for DCS persists (10) based on their anti-inflammatory action $(5,42)$ and because some trials showed long-term benefits from MP in patients suffering from spinal cord trauma (6). Treatment of DCS with another glucocorticoid, Dexamethasone, did not appear to influence the outcome of DCS (20). We used a rat model of DCS to test the predive administration of MP using our dive protocol that favors neurological symptoms of DCS.

\section{Alpha-Phenyl-N-Tert-Butylnitrone (PBN)}

A nitrone-based free radical trap, $\mathrm{PBN}$ reacts covalently with reactive $\mathrm{O}_{2}$ species (ROS) to form stable nitroxiàes. A stuajy examining tissue distribution, excretion, and metabolism of PBN showed that PBN is rapidly absorbed, widely distributed, and remains for a lengthy period in many tissues when injected intraperitoneally in mice (28). Nitrones are neuroprotective in rodent models of central nervous system ischemia (8) and transient compression of the spinal cord (19). Significant protection was evident with administration as late as $12 \mathrm{~h}$ post-ischemia. PBN also minimized ferrous ioninduced seizures and delayed time to death in mice when given $20 \mathrm{~min}$ prior to iron injections (33). The nitronebased free radical scavengers have demonstrated potent neuroprotection in stroke models in which oxidative stress plays a key role (25). The therapeutic mechanism 
of neuroprotection from nitrones is unknown, but current research suggests two major hypotheses: 1) mass-action free radical trapping; and 2) inhibition of enhanced signal transduction associated with neuroinflammatory processes.

\section{Transsodium Crocetinate (TSC)}

TSC is a carotenoid compound. It is a long molecule and computer models suggest that it affects the structure of water (23). For example, crocetin, a similar molecule, forms a hydration shell that has been suggested to increase $\mathrm{O}_{2}$ diffusivity. Molecular dynamics simulations suggest that the mechanism is due to the interactions of the hydrophobic TSC molecules and plasma (23). If plasma is the postulated site of major diffusive resistance to $\mathrm{O}_{2}$ transport between erythrocytes and tissue (26), then it might be helpful to increase diffusivity. The diffusivity of $\mathrm{O}_{2}$ through plasma is lower than it is through water, perhaps due to the presence of plasma proteins (36). Although TSC has not been extensively studied, crocetin has been examined in a number of $\mathrm{O}_{2}$-related experiments and was shown to increase $\mathrm{O}_{2}$ diffusivity through plasma by $30 \%$ (23). Unlike fluorocarbons or hemoglobin, crocetin does not bind $\mathrm{O}_{2}$ or increase its solubility in blood plasma but increases $\mathrm{O}_{2}$ consumption during hemorrhagic shock (24). TSC increased mean arterial blood pressure immediately and reduced tachycardia in a rat model of hemorrhagic shock (24). Some have suggested that when given during resuscitation from hemorrhage, crocetin restores cellular energy levels and reduces apoptosis (46). Interestingly, it has been suggested that TSC and $\mathrm{O}_{2}$ therapy show similar results when used in a rat hemorrhage model (24). We tested a high and a low dose of TSC administered predive as a prophylaxis against DCS in a rat model that favors neurological symptoms of DCS. The dosages of TSC were similar to those used in hemorrhagic shock studies.

This study explored pharmacological interventions described above in rat models of DCS. Our goal was to systematically examine whether any of these drugs held promise as a means of reducing the incidence or severity of DCS.

\section{METHODS}

\section{Animals}

Male Sprague-Dawley rats (Rattus norvegicus, 240-311 g) were examined on receipt by the veterinary staff and housed in the animal care facility. They were stabilized for $7 \mathrm{~d}$, and maintained under a 12-h light/dark cycle with ad libitum access to standard rat chow and water prior to the experiment. The experiments reported were conducted according to the principles set forth in the "Guide for the Care and Use of Laboratory Animals," Institute of Laboratory Animal Resources, National Research Council, National Academy Press. The Institutional Animal Care and Use Committee reviewed and approved all aspects of this protocol. The institutional animal care facility is fully AAALAC accredited.
The mean body mass ( \pm SD) immediately before dive experiments was $271 \pm 18 \mathrm{~g}$ for all animals, and the body mass for each treatment and control group pairs were closely matched in body mass (means within $0-9 \mathrm{~g}$ of each other, with SDs per group of $1-6 \mathrm{~g}$ ).

\section{Drug Treatments}

Each treatment regimen had its own control group and animals were randomly assigned either treatment or control groups. In experiments that required venous access, animals had a small-gauge cannula placed in the tail vein. Sterile saline was used as a flush and control injectate in all control groups.

Lidocaine was delivered either immediately predive $\left(\mathrm{L}_{\text {pre, }}, 1.2 \mathrm{mg} \cdot \mathrm{kg}^{-1}\right)$ or $5 \mathrm{~min}\left(1.2 \mathrm{mg} \cdot \mathrm{kg}^{-1}\right), 10 \mathrm{~min}(0.12$ $\left.\mathrm{mg} \cdot \mathrm{kg}^{-1}\right)$, and $15 \mathrm{~min}\left(0.12 \mathrm{mg} \cdot \mathrm{kg}^{-1}\right)$ after the start of decompression $\left(\mathrm{L}_{\text {post }}\right)$. This low dose was selected to allow animals to remain able to walk, despite the anesthetic properties of lidocaine (7). ASA was dissolved in water and administered by gavage at a dose of $100 \mathrm{mg}$. $\mathrm{kg}^{-1}$ three times daily for $2 \mathrm{~d}$ before dive experiments $(3,40)$. A gavage of water of the same volume and timing as the aspirin treatments was used for the controls. MP $\left(20 \mathrm{mg} \cdot \mathrm{kg}^{-1}\right.$ ) was injected i.v. $4.5 \mathrm{~h}$ before the dive to allow the drug to reach its peak at the time of decompression $(27,36)$. PBN was injected at a dose of $150 \mathrm{mg} \cdot \mathrm{kg}^{-1}$ i.p. immediately predive $(11,19,25,28)$.

TSC solutions were distilled, de-ionized water to which $0.0001 \mathrm{M}$ sodium carbonate had been added drop-wise until the $\mathrm{pH}$ was 8.0 and were injected i.v. TSC was administered i.v. immediately upon reaching the surface and a second dose was given $15 \mathrm{~min}$ later at either a high $\left(\mathrm{TSC}_{\text {high }}, 0.81 \mathrm{mg} \cdot \mathrm{kg}^{-1}\right)$ or low dose $\left(\mathrm{TSC}_{\text {low }}\right.$ $\left.0.27 \mathrm{mg} \cdot \mathrm{kg}^{-1}\right)$. This dose is higher than the threshold dose of $0.1-0.2 \mathrm{mg} \cdot \mathrm{kg}^{-1}$ and lower than the maximum tested without deleterious side effects (24).

\section{Dive Protocols}

Dive protocols were derived from the work of Lillo et al., with pressure and duration selected for a high incidence of DCS in untreated rats of this body mass (29). Rats were exposed in groups of 4 per dive, approximately 40 per experimental group, for a total of 633 animals for this study. The animals were placed in a wire mesh cylindrical drum divided into separate sections along the axis of rotation, one rat per section. The drum was placed inside a hyperbaric chamber and rotated at $3.6 \mathrm{~m} \cdot \mathrm{min}^{-1}$, obligating the rats to walk at a moderate pace during and after the exposure. Two general dive profiles were used with the intention of causing rats to have a high incidence of DCS, with some variation in the frequency of either pulmonary or neurological DCS symptoms (30). It has previously been shown that a compression to $150-200 \mathrm{fsw}$ for $60 \mathrm{~min}$ with a decompression rate at $60 \mathrm{fsw} \cdot \mathrm{min}^{-1}$ results in a high incidence of pulmonary DCS in addition to neurological symptoms. A similar dive depth and duration but with a much more rapid decompression, within $30 \mathrm{~s}$, is likely to induce primarily neurological DCS symptoms (29). 
Compression and decompression schedules for each of the treatment groups were as follows:

The $\mathrm{L}_{\text {pre }}, \mathrm{ASA}_{\text {rapid, }}$ and PBN groups were compressed to $220 \mathrm{fsw}$ (7.67 ATA) for $90 \mathrm{~min}$ and decompressed at a rate of $\sim 15 \mathrm{ATA} \cdot \mathrm{min}^{-1}(<30 \mathrm{~s})$. The $\mathrm{L}_{\text {post }}$ and $\mathrm{ASA}_{\text {slow }}$ groups were compressed to $231 \mathrm{fsw}$ (8.0 ATA) for $90 \mathrm{~min}$ and decompressed at a rate of $60 \mathrm{fsw} \cdot \mathrm{min}^{-1}$. The MP group was compressed to $231 \mathrm{fsw}$ (8.0 ATA) for $90 \mathrm{~min}$ and decompressed at a rate of $\sim 15 \mathrm{ATA} \cdot \mathrm{min}^{-1}(<30 \mathrm{~s})$. The $\mathrm{TSC}_{\text {low }}$ and $\mathrm{TSC}_{\text {high }}$ dose groups were compressed to $175 \mathrm{fsw}$ (6.3 ATA) for $60 \mathrm{~min}$ and decompressed at a rate of $\sim 15 \mathrm{ATA} \cdot \mathrm{min}^{-1}(<30 \mathrm{~s})$.

The animals were observed throughout the dive via ports on the chamber. Immediately post-decompression, the drum was removed from the chamber but continued to rotate for $30 \mathrm{~min}$ at the same speed, with a mill on the laboratory benchtop. Onset of DCS was recorded to the nearest 30 s by a dedicated observer who was not blinded to the treatment. Signs and symptoms of neurological DCS included limping, sideways gait, failure to maintain balance, falling, difficulty righting after a fall, or rolling passively; signs of pulmonary DCS were abnormal breathing. After the 30-min observation period, all surviving animals were euthanized by injection of pentobarbital.

\section{Statistical Analysis}

Mean values reported are $\pm 1 \mathrm{SE}$. Significance was established at the $P<0.05$ level. Group differences in mean time to DCS onset and death (Table I) were analyzed by a single factor analysis of variance (ANOVA).

The measure of effect for treatment efficacy was the difference between the control and drug incidence for DCS and mortality. StatXact with Cytel Studio (Version 6; Cytel, Cambridge, MA) was used to compute exact $95 \%$ confidence intervals $(\mathrm{CI})$ on the difference between the proportions of events in the control group minus the proportion of events in the treated group. Differences in time to onset between control and treated animals were examined by constructing Kaplan-Meier curves; the log rank test was used to assess significance in survival.

\section{TABLE I. TIME TO ONSET OF DCS OR DEATH IN EACH} PROTOCOL.

\begin{tabular}{|c|c|c|c|c|}
\hline \multirow[b]{2}{*}{ Treatment } & \multicolumn{2}{|c|}{ 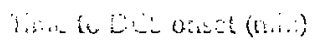 } & \multicolumn{2}{|c|}{ 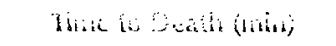 } \\
\hline & Control & Treated & Control & Treated \\
\hline $\mathrm{L}_{\text {pre }}$ & $4.3 \pm 0.3$ & $4.6 \pm 0.4$ & $6.0 \pm 0.5$ & $6.8 \pm 0.5$ \\
\hline$L_{\text {post }}^{\text {po }}$ & $8.9 \pm 0.3$ & $9.4 \pm 0.7$ & $11.8 \pm 0.7$ & $11.0 \pm 0.7$ \\
\hline $\mathrm{ASA}_{\text {rapid }}$ & $6.0 \pm 0.7$ & $5.6 \pm 0.8$ & $8.5 \pm 0.9$ & $8.6 \pm 1.1$ \\
\hline $\mathrm{ASA}_{\text {slow }}$ & $10.3 \pm 0.7$ & $9.3 \pm 0.6$ & $14.2 \pm 1.0$ & $11.4 \pm 0.6$ \\
\hline MP & $4.8 \pm 0.6$ & $5.5 \pm 0.6$ & $5.4 \pm 0.6$ & $7.1 \pm 0.6^{*}$ \\
\hline PBN & $4.1 \pm 0.5$ & $3.0 \pm 0.3$ & $5.2 \pm 0.5$ & $5.9 \pm 0.6$ \\
\hline TSC $_{\text {high }}$ & $6.6 \pm 0.8$ & $6.6 \pm 1.1$ & $9.0 \pm 1.1$ & $12.0 \pm 4.6$ \\
\hline TSC low & $5.0 \pm 0.8$ & $5.0 \pm 0.7$ & $7.3 \pm 1.0$ & $7.1 \pm 0.6$ \\
\hline
\end{tabular}

* Significantly different from paired control group, $P<0.05$.

Symbols: lidocaine pre- $\left(L_{\text {pre }}\right)$ or post-dive $\left(\mathrm{L}_{\text {post }}\right) ;$ ispirin, slow decompression $\left(\mathrm{ASA}_{\text {slow }}\right.$ ); aspirin, rapid decompression $\left(\mathrm{ASA}_{\text {rapid }}\right)$; methylprednisolone (MP); alpha-phenyl- $\mathrm{N}$-tert-buty/nitrone (PBN); transsodium crocetinate, low dose ( $\left.\mathrm{TSC}_{\text {low }}\right)$; transsodium crocetinate, high dose $\left(\mathrm{TSC}_{\text {high }}\right)$.
Since the mean predive weight for control and treatment groups were similar, the crude (i.e., unadjusted) estimates of hazard ratios were calculated.

\section{RESULTS}

Figs. 1A and B summarize the drugs tested based on $95 \% \mathrm{CI}$ on the difference between the proportion of events between the control and drug treatment groups. Differences $>0$ indicate evidence of treatment benefit. All CIs failed to exclude zero; thus none of the drugs reached statistical significance at the $P=0.05$ level. For $L_{\text {post }}$ the estimated confidence interval on the difference in DCS proportions lay almost entirely (97.6\%) to the right of zero, but there was no difference in mean

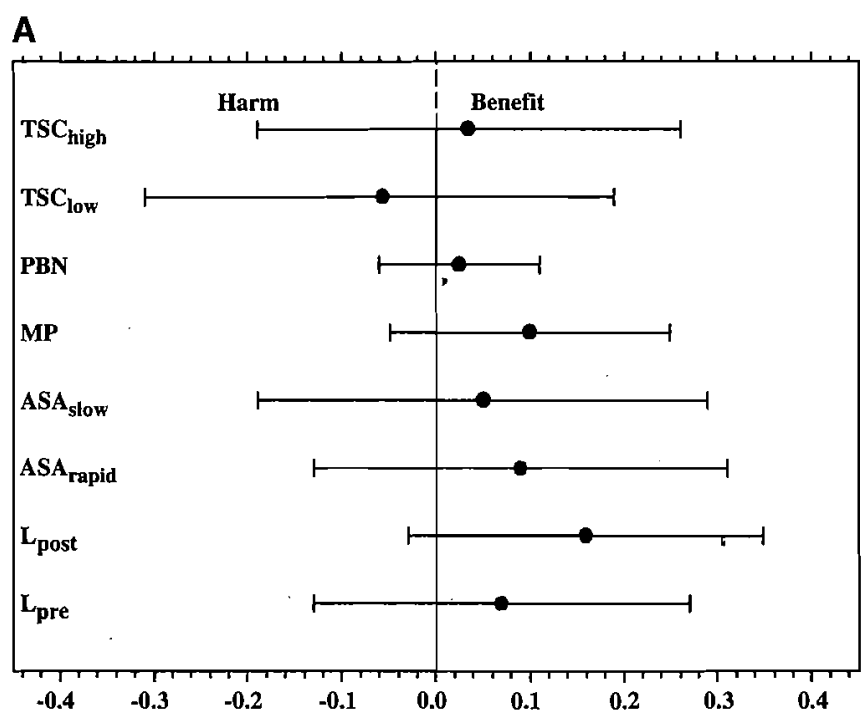

B

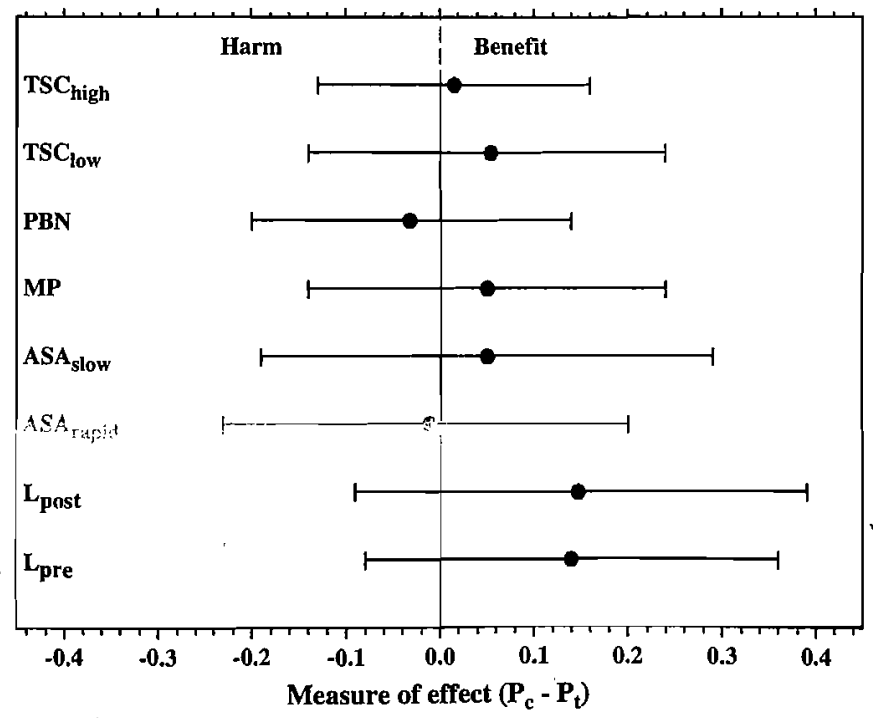

Fig. 1. Treatment effect on DCS A) incidence and B) death. Measure of effect $=p_{c}$ (control) minus $p_{s}$ (treatment), where $p$ is incidence rate. Solid circles show means; bars indicate $95 \%$ confidence intervals. Treatments were: lidocaine pre- $\left(L_{\text {pre }}\right)$ or post-dive $\left(L_{\text {post }}\right)$; aspirin, slow decompression ( $\mathrm{ASA}_{\text {slow }}$ ); aspirin, rapid decompression $\left(\mathrm{ASA}_{\text {rapid }}\right)$; methylprednisolone $(\mathrm{MP})$; alpha-phenyl-N-tert-butylnitrone $(\mathrm{PBN})$; transsodium crocetinate, low dose ( $\left.\mathrm{TSC}_{\text {low }}\right)$; transsodium crocetinate, high dose $\left(\mathrm{TSC}_{\text {high }}\right)$. 
DCS incidence $\left(\chi^{2}=3.1, P<0.1\right)$. Methylprednisolone was the only other treatment associated with a $P$-value $<0.15\left(\chi^{2}=2.2, P<0.15\right)$. With regard to contrasting death rates between the control and treated groups (Fig. 1B), all eight treatments produced two-sided $P$-values $>$ 0.20 .

Times to onset of DCS symptoms and death for all treatment groups are presented in Table I. For MP, there was a statistically longer mean time to onset of death compared to controls $(7.1 \pm 0.6$ versus $5.4 \pm 0.6 \mathrm{~min}$; $\left.\chi^{2}=3.9, P<0.05\right)$. A log-rank survival analysis showed that there was a significantly $(P<0.05)$ longer time to onset of DCS in the MP group (Fig. 2). However, the survival analysis (not significantly different, $P>0.10$ ) did not agree with the test of mean time to death with MP treatment. The only other drug treatment with marginally longer time to onset of DCS compared to controls was the $L_{\text {post }}$ group $\left(\chi^{2}=2.8, P<0.1\right)$.

The mechanisms of action for ASA and lidocaine suggested that these drugs might have a differential effect on physiological processes that would be evident in neurological vs. pulmonary manifestations of DCS. Consequently, two different compression and decompression schedules were used, with the expectation that the slower decompression rate would yield a greater incidence of pulmonary DCS $\left(\mathrm{L}_{\text {pre }}\right.$ and $\left.\mathrm{L}_{\text {post }}\right)$. Table II presents these results by neurological (limping, limb paralysis, seizures) and pulmonary (labored breathing, coughing) symptoms. Many animals displayed both sets of symptoms; consequently their sum does not equal the total DCS for each group.

There were no significant differences between control and treated animals in the incidence of neurological versus pulmonary DCS for either decompression profile of ASA or for the $\mathrm{L}_{\text {pre }}$ group $\left(P>0.20,1\right.$ d.f., $\chi^{2}$ test; Table II). However, in the $L_{\text {post }}$ there were significantly fewer neurological manifestations of DCS compared to controls $\left(51 \%\right.$ versus $73 \%$; $P<0.05,1$ d.f., $\chi^{2}=4.1$; Table II), and a trend toward fewer pulmonary symptoms $(66 \%$ versus $46 \% P<0.10,1$ d.f., $\chi^{2}=3.2$; Table II).

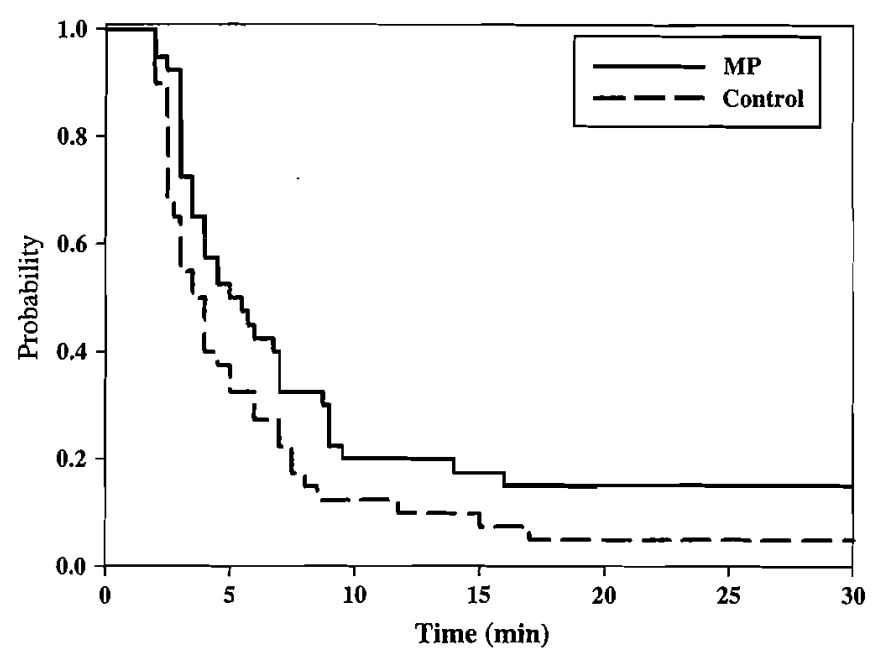

Fig. 2. Kaplan-Meier plot of time to onset of DCS after returning to 1 ATA (Time 0) for animals treated with MP versus controls. Log-rank $P$-value $<0.05$
TABLE II. INCIDENCE OF DCS BY SYMPTOMS (NEUROLOGICAL AND PULMONARY) IN TREATMENT GROUPS WITH COMPRESSION/DECOMPRESSION SCHEDULES DESIGNED

TO HAVE DIFFERING DISTRIBUTIONS OF THESE SYMPTOMS.

\begin{tabular}{|c|c|c|c|c|c|c|}
\hline \multirow[b]{2}{*}{ Treatment } & \multicolumn{2}{|c|}{$\begin{array}{l}\text { Number of animals } \\
\text { per group (n) }\end{array}$} & \multicolumn{2}{|c|}{$\begin{array}{l}\text { Neurological } \\
\text { DCS }(\%)\end{array}$} & \multicolumn{2}{|c|}{$\begin{array}{l}\text { Pulmonary } \\
\text { DCS }(\%)\end{array}$} \\
\hline & Control & Treated & Control & Treated & Control & Treated \\
\hline$L_{\text {pre }}$ & 43 & 43 & 81 & 74 & 21 & 28 \\
\hline$L_{\text {post }}^{\text {pre }}$ & 41 & 39 & 73 & $51^{*}$ & 66 & $46^{+}$ \\
\hline ASA $_{\text {rapid }}$ & 41 & 42 & 76 & 67 & 15 & 12 \\
\hline $\mathrm{ASA}_{\text {slow }}$ & 40 & 40 & 45 & 35 & 60 & 45 \\
\hline
\end{tabular}

* Significantly different $(P<0.05)$ from paired control group.

${ }^{\dagger}$ Trend $(P<0.10)$ toward difference from paired control group.

Symbols: lidocaine pre- $\left(\mathrm{L}_{\text {pre }}\right)$ or post-dive $\left(\mathrm{L}_{\text {post }}\right)$; aspirin, slow decompression $\left(\mathrm{ASA}_{\text {slow }}\right)$; aspirin, rapid decompression ( $\left(\mathrm{SA}_{\text {rapid }}\right)$.

\section{DISCUSSION}

Since recognizing DCS as a possible inflammatory response, rather than a phenomenon exclusive to gas supersaturation and bubble load, researchers have pursued drug therapies targeting the inflammatory cascade (5). While recompression followed by controlled decompression is standard treatment, an effective adjunctive therapy could prevent or minimize secondary pathophysiological pathways. Our research examined several current leading candidates.

Lidocaine was chosen for its myriad effects on membranes and mediation of inflammation. Our data suggest that lidocaine has no effect on DCS incidence when given predive (Table II; Fig. 1). However, our data also indicated a trend that survival time before DCS was longer in the $\mathrm{L}_{\text {post }}$ group, suggesting some temporary individual benefit, but no general benefit in this animal model. $\mathrm{L}_{\text {post }}$ rats showed a trend toward lower DCS incidence (Fig. 1), and a statistically significant reduction of neurological DCS (Table II). We opted to use a conventional low dose of lidocaine (33) that permitted animals to walk, versus higher anesthetic doses that might have left animals unable to stand. Low dose injection of lidocaine has had neuroprotective effects while higher doses have had inconsistent effects $(7,13,31,33)$. Elevated lidocaine doses decrease cerebral blood flow and lead to metabolic stress (33), and would be impractical as a predive prophylactic if it left divers unable to work. It is uncertain if higher doses than we tested post-dive would lead to a statistically significant reduction in DCS. It may be useful to test higher doses of $\mathrm{L}_{\text {post }}$ to produce plasma levels of $1-2 \mu \mathrm{g} \cdot \mathrm{ml}^{-1}(44)$. It may also be worth examining lidocaine in a larger animal model with physiological monitoring to determine the modes of action and the possibility of augmenting beneficial effects.

Our results corroborate those of Bennett and Brock (3) that ASA did not alter the incidence of DCS or death, but differ from Popovic et al. (41), who found a significant reduction in DCS following ASA administration. The dosage we tested was nearly double that of Popovic et al., but we administered ASA for $3 \mathrm{~d}$ predive, versus $30 \mathrm{~d}$ predive in the Popovic et al. study. Our dives saturated the rats with nitrogen (29), whereas the Popovic dives 
were of $30 \mathrm{~min}$ duration, which is subsaturated. We do not know how these differences in protocol may have contributed to the disparate results.

The ineffectiveness of ASA against DCS may be due to its inability to inhibit leukocyte activation and adherence. There has been some speculation that inhibition of platelet activation by ASA might exacerbate neurological DCS if there is bleeding in neurological tissues caused by bubble damage. Due to its ubiquitous use, it is important to note that this study finds that ASA administered prior to hyperbaric exposure does not increase the incidence of either neurological or cardiopulmonary DCS.

Our results show that MP might offer benefit as an adjuvant treatment for DCS in a rat model. MP caused a statistically significant delay in the onset of DCS (Fig. 2), but DCS incidence was the same in treated and control animals. Although high-dose MP is commonly administered after spinal cord injury, this is not the case with DCS. While MP has never been tested in humans for DCS, animal studies show that it did not protect against severe DCS; in fact, treated animals with DCS had higher mortality (14). In addition, there are potentially serious adverse reactions to the use of parenteral corticosteroids, such as gastrointestinal bleeding and pancreatitis. Mega-dose MP has been associated with anaphylaxis, hyperglycemia, infection, bradycardia, exacerbation of hypertension, seizure, and sudden death (21).

PBN alleviates oxidative damage from ischemia/ reperfusion injury by efficiently trapping ROS. ROS protect biologically important molecules from oxidative damage. While $\mathrm{O}_{2}$ free radicals and oxidative events have been implicated in DCS, there is no definitive proof that they are a main component of DCS. Our results are the first to show that a nitrone-based free radical scavenger has no effect on the incidence of DCS. Our doses were higher than those in the literature investigating ischemia/reperfusion and stroke (11). PBN's ineffectiveness suggests that the formation of free radicals may not be important in DCS pathology.

Although TSC has shown promise in the treatment of hemorrhagic shock, our results indicate that it is not beneficial in the treatment of DCS. Treatment with $100 \%$ $\mathrm{O}_{2}$ is a widely used option for DCS treatment outside of recompression, thought to be due to enhancement of $\mathrm{N}_{2}$ off-gassing and the increase in the capillary partial pressure of $\mathrm{O}_{2}(45)$. Experience with $100 \% \mathrm{O}_{2}$ breathing at 1 AIA is limuted andinecolal since no cinicai triais have been performed. However, it is thought that breathing $100 \% \mathrm{O}_{2}$ may relieve the symptoms of DCS and decrease the number of decompression treatments needed (45). TSC reputedly increases $\mathrm{O}_{2}$ diffusivity, but is ineffective in the treatment of DCS.

\section{Conclusion}

The need for further research in DCS adjunctive therapy is obvious. Human trials are ethically problematic due to the low incidence of DCS, emphasizing the importance of continued animal research. The ineffectiveness of the therapeutic agents we tested and the mar- ginal results with lidocaine post-dive are convincing evidence that the hunt for an appropriate drug strategy against DCS will not be easy. While the results of this study do not support the use of any of these compounds in severe DCS, they may be useful in milder forms of the disease. Future studies should consider investigating adjuvants given in combinations. Since DCS is multipleorgan pathology, it may require two or three drugs impacting on different pathological mechanisms to attenuate or prevent DCS. Another area of future research should be adjuvant therapy during recompression and high-pressure $\mathrm{O}_{2}$ breathing. While the general incidence of DCS among Navy and sport divers is low, its impact can be severe and long lasting. An efficacious treatment or intervention could significantly impact military, commercial, and recreational divers, ameliorating the occurrence and sequelae of this disease.

\section{ACKNOWLEDGMENTS}

The authors thank Dr. John Gainer for kindly supplying the TSC. We also wish to thank Mr. William Porter, Mr. Donald Valentine, Mr. Daniel Brown, Mr. Melvin Routh, Mr. Darren Fryer, and Mr. Wayne Koller for their excellent technical assistance. Thanks are also due to the staff of the Laboratory Animal Medicine and Science Department and Technical Services Department at NMRC. We are also grateful to Ms. Diana Temple for her help in preparation of the manuscript. Special thanks to Bob Burge and Lanju Zhang, MS, for statistical analysis and helpful comments to the manuscript.

This work was supported by Office of Naval Research work units 62236N.4122.1M20.A0071 and 63706N0096.1330.A0071, IACUC KO05-00. The opinions and assertions contained herein are those of the authors and are not to be construed as official or reflecting the views of the Navy Department or the naval service at large.

\section{REFERENCES}

1. Bennett M, Mitchell S, Dominguez A. Adjunctive treatment of decompression illness with a non-steroidal anti-inflammatory drug (Tenoxicam) reduces compression requirement. Undersea Hyperb Med 2003; 30:195-205.

2. Bennett PB. A review of protective pharmacological agents in diving. Aerosp Med 1972; 43:184-92.

3. Bennett PB, Brock AJ. Action of selected drugs on decompression sickness in rats. Aerosp Med 1969; 40:607-10.

4. Bigger J, Hoffman B. Antiarrhythmic drugs. In: Goodman-Gilman A, Rall T, Nies A, Taylor P, eds. The pharmacological basis of therapeutics. New York: McGraw-Hill; 1990:840-73.

5. Bove AA. The basis for drug therapy in decompression sickness. Undersea Biomed Res 1982; 9:91-111.

6. Bracken MB, Shepard MJ, Collins WF, Holford TR, Young W, Baskin DS, et al. A randomized, controlled trial of methylprednisolone or naloxone in the treatment of acute spinal-cord injury. Results of the Second National Acute Spinal Cord Injury Study. N Engl J Med 1990; 322:1405-11.

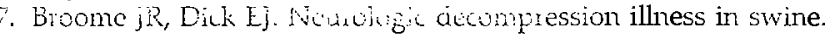
Aviat Space Environ Med 1996; 67:207-13.

8. Cao X, Phillis JW. Alpha-phenyl-N-tert-butyl-nitrone reduces cortical infarct and edema in rats subjected to focal ischemia. Brain Res 1994; 644:267-72.

9. Catron PW, Flynn ET Jr. Adjuvant drug therapy for decompression sickness: a review. Undersea Biomed Res 1982; 9:161-74.

10. Catron PW, Hallenbeck JM, Flynn ET, Bradley ME, Evans DE. Pathogenesis and treatment of cerebral air embolism and associated disorders. Bethesda, MD: Naval Medical Research Institute; 1984. Technical Report 84-20.

11. Choi CW, Hwang JH, Chang YS, Shin SM, Park WS, Lee M. Effects of alpha-phenyl-N-tert-butyl nitrone (PBN) on brain cell membrane function and energy metabolism during transient global cerebralhypoxia-ischemia and reoxygenation-reperfusion in newborn piglets. J Korean Med Sci 2004; 19:413-8.

12. Cogar WB. Intravenous lidocaine as adjunctive therapy in the treatment of decompression. Ann Emerg Med 1997; 29:284-6. 
13. Drewry A, Gorman DF. Lidocaine as an adjunct to hyperbaric therapy in decompression illness: a case report. Undersea Biomed Res 1992; 19:187-90.

14. Dromsky DM, Weathersby PK, Fahlman A. Prophylactic high dose methylprednisolone fails to treat severe decompression sickness in swine. Aviat Space Environ Med 2003; 74:21-8.

15. Dromsky DM, Toner CB, Fahlman A, Weathersby PK. Prophylactic treatment of severe decompression sickness with methylprednisolone [Abstract]. Undersea Hyperb Med 1999; 26(Suppl.): 15 .

16. Dutka AJ, Francis TJ. Pathophysiology of decompression sickness. In: Bove AA, ed. Diving medicine. Philadelphia: WB Saunders; 1997:159-175.

17. Dutka AJ, Mink RB, Pearson RR, Hallenbeck JM. Effects of treatment with dexamethasone on recovery from experimental cerebral arterial gas embolism. Undersea Biomed Res 1992; 19:131-41.

18. Evans DE, Kobrine AI, LeGrys DC, Bradley ME. Protective effect of lidocaine in acute cerebral ischemia induced by air embolism. J Neurosurg 1984; 60:257-63.

19. Farooque M, Olsson $Y$, Hillered L. Pretreatment with alpha-phenylN-tert-butyl-nitrone (PBN) improves energy metabolism after spinal cord injury in rats. J Neurotrauma 1997; 14:469-76.

20. Francis TJR, Dutka AJ, Clark JB. An evaluation of dexamethasone in the treatment of acute experimental spinal decompression sickness. Proceedings of the $9^{\text {th }}$ International Symposium on Underwater and Hyperbaric Physiology; September 1986; Kobe, Japan. Bethesda, MD: Undersea and Hyperbaric Medical Society; 1987:999-1012.

21. Francis TJ, Dutka AJ. Methyl prednisolone in the treatment of acute spinal cord decompression sickness. Undersea Biomed Res 1989; 16:165-74.

22. Francis TJ, Mitchell SJ. Pathophysiology of decompression sickness. In: Brubakk AO, Newman TS, eds. Physiology and medicine of diving. New York: Sanders; 2003:530-66.

23. Gainer JL, Rudolph DB, Caraway DL. The effect of crocetin on hemorrhagic shock in rats. Circ Shock 1993; 41:1-7.

24. Giassi LJ, Gilchrist MJ, Graham MC, Gainer JL. Trans-sodium crocetinate restores blood pressure, heart rate, and plasma lactate after hemorrhagic shock. J Trauma 2001; 51:932-8.

25. Gray C, Nukada H, Jackson DM, McMorran PD, Wu A, Ma F. Neuroprotective effects of nitrone radical scavenger S-PBN on reperfusion nerve injury in rats. Brain Res 2003; 982: 179-85.

26. Holland RA, Shibata $\mathrm{H}$, Scheid P, Piiper J. Kinetics of $\mathrm{O}_{2}$ uptake and release by red cells in stopped-flow apparatus: effects of unstirred layer. Respir Physiol 1985; 59:71-91.

27. Jarden JO, Dhawan V, Moeller JR, Strother SC, Rottenberg DA. The time course of steroid action on blood-to-tumor transport of $82 \mathrm{Rb}$ : a positron emission tomographic study. Ann Neurol 1989; 25:239-45.

28. Lee JH, Park JW. Protective role of alpha-phenyl-N-t-butylnitrone against ionizing radiation in U937 cells and mice. Cancer Res 2003; 63:6885-93

29. Lillo RS, Flynn ET, Homer LT. Decompression outcome following saturation dives with multiple inert gases. J Appl Physiol 1985; 59:1503-14.
30. Lillo RS, MacCallum ME. Decompression comparison of $\mathrm{N}_{2}$ and $\mathrm{O}_{2}$ in rats. Undersea Biomed Res 1991; 18:317-31.

31. Lyle CB, Dahl EV. Protection of rapidly decompressed rats by pharmacologic and physical means. Am J Physiol 1961; 201: $759-61$.

32. MacGregor RR, Thorner RE, Wright DM. Lidocaine inhibits granulocyte adherence and prevents granulocyte delivery to inflammatory sites. Blood 1980; 56:203-9.

33. Martin JD, Thom SR. Vascular leukocyte sequestration in decompression sickness and prophylactic hyperbaric oxygen therapy in rats. Aviat Space Environ Med 2002; 73:565-9.

34. Mitchell SJ. Lidocaine in the treatment of decompression illness: A review of the literature. Undersea Hyperb Med 2001; 28:165-74.

35. Moon RE. Treatment of decompression sickness and arterial gas embolism. In: Bove AA, ed. Diving medicine. Philadelphia: W. B. Saunders; 1997:184-204.

36. Navari RM, Hall KR, Gainer JL. Effect of plasma proteins on diffusion. In: Hershey D, ed. Blood oxygenation. New York: Plenum Press; 1970:243-61.

37. Nishina $K$, Mikawa K, Takao Y, Shiga M, Maekawa N, Obara H. Intravenous lidocaine attenuates acute lung injury induced by hydrochloric acid aspiration in rabbits. Anesthesiology 1998; 88:1300-9.

38. Nyquist PA, Dick EJ Jr, Buttolph TB. Detection of leukocyte activation in pigs with neurologic decompression sickness. Aviat Space Environ Med 2004; 75:211-4.

39. Patrono C. Efficacy and safety of aspirin in the long-term management of atherothrombosis. Haematologica 2001; 86(11, Suppl. 2):19-21.

40. Philp RB, Bennett PB, Anderson JC, Fields GN, McIntyre BA, Francey I, Briner W. Effects of aspirin and dipyridamole on platelet function, hematology and blood chemistry of saturation divers. Undersea Biomed Res 1979; 6:127-46.

41. Popovic P, Popovic V, Honeycutt C. Levodopa and aspirin pretreatment beneficial in experimental decompression sickness. Proc Soc Exp Biol Med 1982; 169(1):140-3.

42. Roy JW, Graham MC, Griffin AM, Gainer JL. A novel fluid resuscitation therapy for hemorrhagic shock. Shock 1998; 10: 213-7.

43. Sakurai M, Mannen T, Kanazawa I, Tanabe H. Lidocaine unmasks silent demyelinative lesions in multiple sclerosis. Neurology 1992; 42:2088-92.

44. Spiegel DA, Dexter F, Warner DS, Baker MT, Todd MM. Central nervous system toxicity of local anesthetic mixtures in the rat. Anesth Analg 1992; 75:922-8.

45. Thalmann ET. Use of $100 \%$ surface oxygen in treatment of DCI. In: Moon RE, ed. Adjunctive therapy for decompression illness. Kensington: Undersea and Hyperbaric Medical Society; 2003: 129-32.

46. Van Way CW $3^{\text {rd }}$, Dhar A, Morrison DC, Longorio MA, Maxfield DM. Cellular energetics in hemorrhagic shock: restoring adenosine triphosphate to the cells. J Trauma 2003; 54(5, Suppl.)S16976.

47. Vane JR, Botting RM. The mechanism of action of aspirin. Thromb Res 2003; 110(5-6):255-8.

48. Weissman G, ed. Mediators of inflammation. New York: Plenum Press; 1974 . 